\title{
The Influence of Social Media on the Empathy Levels of Chinese Secondary Students
}

\author{
Chen Shen ${ }^{1}$ \\ ${ }^{1}$ The Webb schools, California, USA \\ Correspondence: Chen Shen, The Webb schools, 1175 West Baseline Road, Claremont, CA 91711, USA.
}

Received: May 10, 2018

doi:10.5539/ijps.v10n3p7
Accepted: June 10, 2018

URL: https://doi.org/10.5539/ijps.v10n3p7

Online Published: June 15, 2018

\begin{abstract}
Social media today exerts a substantial impact on how people view various social issues, especially among secondary students, the heaviest users of social media. This paper, based on empirical studies on the time and frequency of teenagers' social media use, as well as the way they use social media to "follow" certain topics, attempts to address how social media influences the levels of empathy in secondary students. First-hand data of questionnaires and interviews are collected among secondary students in Foshan, Guangdong, China. The data is used to analyze the extent to which using different media platforms or following different content can result in different empathy levels.
\end{abstract}

Keywords: empathy, Foshan, secondary students, social media

\section{Introduction}

There have been several research papers on the impacts of social media. For example, Monica Anderson at the Pew Research Center finds that social media can change people's views on sociopolitical issues. Approximately $20 \%$ of respondents claim that social media changes their views on sociopolitical issues, and $17 \%$ respondents believe that social media changes their views on political candidates. Furthermore, social media influences people's satisfaction with several aspects of social life, such as democracy, health care policies, and education. (Anderson, 2016)

Andrea Ceron suggests that Europeans who acquire news from social media typically feel more satisfied with the current democracy than those who acquire news from professional news media. (Ceron, 2016)

Another paper by Alloway analyzes the relationship between the use of Facebook and user's levels of empathy and narcissism. Using questionnaires conducted on Facebook, researchers find that certain Facebook functions like selfies and photo sharing may lead to narcissism and that functions like chat may intensify the discord between the two sexes. The study suggests that Facebook, one of the largest social media platforms, may influence people's behavior by changing their psychological status. (Alloway, 2014)

Chinese researchers suggest that the network communication platforms can play a major role in understanding today's college students and guiding through their cognitive and moral development. (Zhang, 2012)

The aforementioned studies employ a common method - questionnaires - to acquire information. Also, they compare the results of these questionnaires to find similarities and trends. All of these studies reveal that social media changes people's behavior and perspectives, although the precise mechanism of this change still remains unclear.

The results from these studies will be compared with the results of this paper.

\section{Methods}

\subsection{Basic Concepts and Theory Scope}

Empathy, defined in a number of ways though, is generally seen as ability to understand and share the feelings of others. Empathy arises either because people have a common goal or because their personal benefits are interwoven. Empathy can strongly shape one's cognition and therefore one's ability to form judgement. This paper performs a comparative analysis of the current state of the use of social media, determining the difference between the empathy levels of students in three secondary schools in Foshan. An in-depth analysis of the underlying reasons for the difference in empathy levels, as well as the possible problems that may be caused by a 
lack of empathy, is also discussed. The questionnaire answers are analyzed by dividing variables into two categories; the first category includes the time that users spend on social media, the second includes the type, number, and the sources of online reports that users can access. As the variables in one category are controlled, those in the other category are compared. Thus, each variable influences how users' empathy levels can be measured.

\subsection{Respondents}

The survey is conducted by stratified sampling at the Nanhai Secondary School, Rongshan Secondary School, and Foshan Third Secondary School. 130 questionnaires are circulated and 118 completed and returned, with an effective feedback rate of $90.8 \%$. (Table 1) Meanwhile, seven face-to-face interviews are conducted, and the details are incorporated into the final analysis.

Table 1. General information about the survey

\begin{tabular}{llll}
\hline Location & Questionnaires circulated & Effective feedback & Effective feedback rate \\
\hline Nanhai Secondary School & 50 & 48 & $96.0 \%$ \\
Rongshan Secondary School & 35 & 30 & $85.7 \%$ \\
Foshan Third Secondary School & 45 & 40 & $88.8 \%$ \\
Total & 130 & 118 & $90.8 \%$ \\
\hline
\end{tabular}

\subsection{Questionnaire Design}

The questionnaire has three sections. The first section includes basic questions: "What kind(s) of social media do you use most frequently?" "Why do you use these types of social media?" "What news topics typically grab your attention?" etc. These questions are used as the basis for later analyses.

The second section focuses on time-related issues: "How long do you usually spend on social media?" "When did you start using social media?" he questions in this section help illustrate whether there a correlation exists between time spent on social media and one's level of empathy for others.

The third section focuses on empathy for others: that is, how the respondents reflect on social media on others' living status and social milieu and on controversies that others have experienced. Such reflections may help judge whether the respondents empathize with, or understand, other social media users.

\section{Findings and Analyses}

\subsection{The Current Status of the Use of Social Media}

Social media has become a crucial part of students' daily lives in Foshan. Over $90 \%$ of students have used social media for at least one year, and nearly half have over five years of experience with social media. Moreover, around $85 \%$ spend at least one hour per day on social media, and around $36 \%$ spend over three hours per day. This reveals that that students use social media accounts for a considerable amount of time every day, despite the intense pressure of schoolwork and tests. (Table $2 \& 3$ )

Table 2. Respondents' experience of using social media

\begin{tabular}{ll}
\hline experience of using social media & percentage of respondents \\
\hline below 1 year & $7.63 \%$ \\
$1-3$ years & $28.81 \%$ \\
$3-5$ years & $21.19 \%$ \\
over 5 years & $42.37 \%$ \\
\hline
\end{tabular}

Table 3. Daily average hours spent on using social media

\begin{tabular}{ll}
\hline time spent per day on using social media & percentage of respondents \\
\hline below 1 hour & $16.1 \%$ \\
$1-3$ hours & $47.46 \%$ \\
3-5 hours & $20.34 \%$ \\
over 5 hours & $16.1 \%$ \\
\hline
\end{tabular}

Among the platforms that the respondents frequent, WeChat, QQ, and Microblog reign as the most popular. 
Virtually all respondents use WeChat and $76 \%$ choose it as their most frequently used platform. QQ and Microblog receive considerable percentages of users ( $74 \%$ and $44 \%$, respectively) but are seldom any user's first choice of social media platform. (Table 4)

Table 4. Social media platforms that Foshan students choose

\begin{tabular}{lll}
\hline social medium & $\begin{array}{l}\text { percentage of users who choose it as the } \\
\text { personally most frequently used }\end{array}$ & $73.73 \%$ \\
\hline QQ & $11.86 \%$ & $95.76 \%$ \\
WeChat & $77.97 \%$ & $44.07 \%$ \\
Microblog platforms & $3.39 \%$ & $17.8 \%$ \\
$\begin{array}{l}\text { overseas of users } \\
\text { (e.g. Facebook) }\end{array}$ & $5.93 \%$ & $6.78 \%$ \\
others & $0.85 \%$ & 6 \\
\hline
\end{tabular}

Unlike the overwhelming favoring of one single platform (WeChat), respondents' interest in topics for internet content shows an even and stable distribution. Three quarters of the respondents claim that their focuses have not changed within recent years. While over half of the respondents follow "entertainment" (64\%) and "news" $(57 \%)$, the respondents still show wide interests in "games" (35\%), "cartoons" (35\%), "social life" (33\%), "science and technology" (32\%), and so forth. (Table 5)

Table 5. Contents that Foshan Students follow

\begin{tabular}{lll}
\hline content & percentage of the most interested followers & percentage of followers \\
\hline entertainment & $31.36 \%$ & $64.41 \%$ \\
news & $22.88 \%$ & $56.78 \%$ \\
game & $12.71 \%$ & $34.75 \%$ \\
cartoon & $9.32 \%$ & $34.75 \%$ \\
social life & $4.24 \%$ & $33.05 \%$ \\
science \& technology & $9.32 \%$ & $32.2 \%$ \\
politics & $1.69 \%$ & $23.73 \%$ \\
sports & $5.93 \%$ & $21.19 \%$ \\
finance \& economics & $0.85 \%$ & $20.34 \%$ \\
military affairs & $1.69 \%$ & $14.41 \%$ \\
\hline
\end{tabular}

Likewise, the purposes for which respondents choose to use social media are also diverse: $80 \%$ of them report that they use social media mainly for interesting new information, $58 \%$ for tracking global changes, $39 \%$ for accessing others' opinions, $39 \%$ for entertainment, $36 \%$ simply for killing time, $28 \%$ for finding new friends, and $15 \%$ for jobs. Interestingly, the social media respondents report that social media helps least in their study. (Table 6)

Table 6. Purpose of using social media

\begin{tabular}{ll}
\hline the purpose of using social media & percentage of respondents \\
\hline to learn about interesting new information & $80.51 \%$ \\
to learn about global changes & $57.63 \%$ \\
to learn about opinions from others & $38.98 \%$ \\
to seek entertainment & $38.98 \%$ \\
to purely kill time & $36.44 \%$ \\
to make new friends & $27.97 \%$ \\
to meet the need of future jobs & $15.25 \%$ \\
to help study & $12.71 \%$ \\
\hline
\end{tabular}




\subsection{Behavior and Attitude to the Social Media}

Over $80 \%$ of the respondents choose to comment on what is published on the social media, although most of them only choose to comment on what they are interested in. (Table 7)

Table 7. Answers to the question "Do you often comment on what is published on the social media?"

\begin{tabular}{ll}
\hline Answer & percentage of respondents \\
\hline yes & $17.8 \%$ \\
no & $30.51 \%$ \\
yes, but only on what I am interested in & $51.69 \%$ \\
\hline
\end{tabular}

About one third tend to join the discussion and publish personal ideas about the issues that they follow. Furthermore, only $11 \%$ of respondents tend to directly accept the things they read on the web, whereas most respondents tend to analyze online information and then sift through it to figure out what is trustworthy (70\%), attempt to obtain further knowledge about the interested parties (39\%), read others' posts carefully (45\%), and/or share with others (6\%). (Table 8$)$

Table 8. Answers to the question "What will you do to the issues that you follow?"

\begin{tabular}{ll}
\hline answer & percentage of respondents \\
\hline analyze the online information and then sift the trustworthy part & $70.34 \%$ \\
read in-depth & $44.92 \%$ \\
scan & $41.53 \%$ \\
try to obtain further knowledge of the interested parties & $38.98 \%$ \\
join the discussion & $31.36 \%$ \\
directly accept the voices & $11.02 \%$ \\
others (e.g. share with others, or conduct some investigation, etc.) & $5.93 \%$ \\
\hline
\end{tabular}

\subsection{Empathy Levels of the Students}

The results of this questionnaire reveal a high correlation between empathy and media types used, but a poor correlation between empathy and time spent on this media. For example, one respondent follows games and cartoons on social media for two or three hours every day and has being doing so for six years. Even though this adds up to a huge amount of time, he fails to show a high level of empathy. As he claims, he rarely encounters beliefs that contradict his or anyone who he considers strange, simply because his peers share similar hobbies and lifestyles. By contrast, those who demonstrate deep empathy typically pay attention to sports, art, education, dance, fashion, and news on and off campus. One such respondent spends less than three hours every day on social media, but he can understand that "everyone has a different background, and it is not my business to control how others behave," as he says.

Almost all respondents believe that they can readily understand others' behavior and thoughts and that they can view issues from differing perspectives.

Facing contrasting perspectives, 55\% students consider them carefully and choose the elements that they deem reasonable; $35 \%$ students tend to support one side and try to understand the other; only $8 \%$ directly pick one side over the other unequivocally. (Table 9)

Table 9. Answers to the question "What will you do when viewing two opposite opinions?".

\begin{tabular}{ll}
\hline answer & percentage of respondents \\
\hline support one side and oppose the other & $8.47 \%$ \\
support one side and try to under the other & $34.75 \%$ \\
critique both sides and make a comment & $55.08 \%$ \\
others (please elaborate) & $1.69 \%$ \\
\hline
\end{tabular}

Encountering an argument flatly contradicting their personal values, more than $60 \%$ of students agree at least that the argument is consistent with the facts which the arguer may have observed, and about $8 \%$ even tend to accept the argument rather than immediately rejecting it. (Table 10) 
Table 10. Answers to the question "What will you do when encountering an argument against your personal values?".

\begin{tabular}{ll}
\hline answer & percentage of respondents \\
\hline reject the argument & $19.49 \%$ \\
accept the argument & $8.47 \%$ \\
understand that the argument is based on the facts that the arguer & $61.02 \%$ \\
may have observed & $11.02 \%$ \\
others (please elaborate) & \\
\hline
\end{tabular}

Chances are that familiar persons, such as classmates or friends, make dirty, provocative, or cynical remarks on social media when they are averse to, angry at, or indifferent about school regulations, examinations, parental interference, and so forth. However, most respondents do not choose to deny the observations of these people, but tend to console them $(22 \%)$, notice their emotional fluctuation and communicate with them $(28 \%)$, or at worst ignore them (47\%). (Table 11)

Table 11. Answers to the question "What will you do when you see one who you know makes a harsh remark, one that may be offensive, insulting, cynical, provocative, or so?".

\begin{tabular}{ll}
\hline answer & percentage of respondents \\
\hline cannot understand but try to console them & $22.03 \%$ \\
pay attention to their emotional changes and try to communicate & $27.97 \%$ \\
with them & $47.46 \%$ \\
ignore them & $2.54 \%$ \\
other answers ("That depends." etc.) &
\end{tabular}

Interestingly, however, a considerable proportion of respondents claim that the empathy levels shown by web users are quite low. In their eyes, many web users do not act as consciously and intelligently as the respondents themselves. Thus, only half of the respondents are confident about a lasting harmonious atmosphere on social media platforms; the rest display some pessimism.

\section{Conclusion and Suggestion}

Secondary students in Foshan are heavy users of social media, especially WeChat, QQ, and Microblog. They are not only actively involved in discussing various topics online, but also think and behave carefully and critically in their online interactions. The students demonstrate overall empathy with others, although the empathy levels depend on what content they usually follow rather than how much time they spend online. The underlying reason for this may be that the massive amount of information posted on multiple social media platforms expands users' horizons, familiarizing them with the lives of others. As a result, these social media users may have more empathy.

Admittedly, despite platforms' attempts to censor them, the Internet atmosphere is still spoiled by obnoxious "trolls," who do not feel remorse for using insulting words and arousing controversies, or by "keyboard men," who behaves passively in real-life interpersonal interactions but exhibit aggression against others on the Internet. These people are immune to criticism and logical arguments and are also generally incapable of empathy. Some fanboys and fangirls of celebrities may defame other stars and their fans online. Some other people on social media fabricate pathetic experiences in order to defraud others of trust or sympathy. Not only do these people lack empathy, but they make social media communities untrustworthy.

While social media contains cold, abrasive, hostile sound, these platforms indeed shorten the distance between users and help them better understand each other. The question now is not whether one should use social media to develop empathy or express empathy for others, but rather how one should be taught or guided to opine in a decent manner on the web.

\section{References}

Alloway, T.; Runac, R.; Qureshi, M.; Kemp, G. (2014). Is Facebook Linked to Selfishness? Investigating the Relationships among Social Media Use, Empathy, and Narcissism. Social Networking, 3(3), 150-158. https://doi.org/10.4236/sn.2014.33020

Anderson, M. (2016). Social Media Causes Some Users To Rethink Their Views On An Issue. 
http://www.pewresearch.org/fact-tank/2016/11/07/social-media-causes-some-users-to-rethink-their-views-o n-an-issue/

Ceron, A.; Memoli, V. (2016). Flames And Debates: Do Social Media Affect Satisfaction With Democracy? Social Indicators Research, 126(1), 225.

Zhang, T.T.; Tian, N. (2012). The Influence of Internet Culture on Values of Post-90s University Students and Countermeasures. Journal of Research on Education for Ethnic Minorities, 110(23), 109-114.

\section{Copyrights}

Copyright for this article is retained by the author(s), with first publication rights granted to the journal.

This is an open-access article distributed under the terms and conditions of the Creative Commons Attribution license (http://creativecommons.org/licenses/by/4.0/). 